\title{
UM ESTUDO SOBRE A IMPLEMENTAÇÃO DO PROGRAMA BRASIL QUILOMBOLA NOS POVOADOS RIBEIRA E TABACARIA, ALAGOAS
}

\author{
Pedro Simonard (D)
}

Centro Universitário Tiradentes I Maceió - AL - Brasil

Shymena Brandão César (ID

Centro Universitário CESMAC I Maceió - AL - Brasil

Aristoteles Sales Silva Neto (iD $\triangle$

Lorena Madruga Monteiro (D) $ه$

Centro Universitário Tiradentes I Maceió - AL - Brasil 
RESUMO

Estudos diversos sobre a implementação das políticas que compõem o Programa Brasil Quilombola demonstram que o acesso das comunidades aos benefícios dessas políticas é extremamente restrito. Destacam também a dificuldade de comunicação entre os executores das políticas do programa e as comunidades-alvo delas. Outros estudos demarcam a questão da falta de conhecimento dos membros das comunidades quilombolas acerca dessas políticas, o que dificulta a reivindicação dos direitos assegurados por este programa. Este artigo analisa se as políticas relacionadas ao programa foram implantadas em duas comunidades quilombolas no estado de Alagoas e qual foi o papel dos burocratas nesses processos. Através de pesquisa de campo e de entrevistas com burocratas e gestores das pastas responsáveis pela execução e implementação deste programa nos municípios, mapeou-se quais políticas dentro dos eixos que o integralizam foram implementadas, observando-se o papel desses burocratas na operacionalização e readequação dessas políticas, assim como a percepção da população desses povoados acerca dessas políticas. Conclui-se que estes burocratas têm um papel quase nulo na operacionalização e na melhora dessas políticas quando e se elas são implementadas e que a população desses povoados desconhece os benefícios a que têm direito dentro dos eixos do programa.

Palavras-chave: Programa Brasil Quilombola; agenda social quilombola; quilombolas; burocracia; políticas públicas.

\section{A STUDY ON THE IMPLEMENTATION OF THE BRASIL QUILOMBOLA PROGRAM IN THE RIBEIRA AND TABACARIA VILLAGES, ALAGOA}

Various studies of the implementation of the policies that make up the Brazil Quilombola Program (PBQ) demonstrate that the communities' access to the resources and benefits of these policies is extremely restricted. They also highlight the difficulty of communication between the Program's policy makers and their target communities. Other studies highlight the lack of knowledge of quilombola community members about the policies of the PBQ, what makes it difficult to claim the rights guaranteed by the program. Faced with this scenario, this article analyzes whether the policies related to the PBQ were implemented in two quilombola communities in the state of Alagoas and what was the role of the bureaucrats in these processes. Through field research and interviews with bureaucrats and managers of the departments responsible for implementing the program in the municipalities, we mapped out which policies within the axes that make up the PBQ were implemented, and analyzed the role of these bureaucrats in the operationalization and readjustment of these policies, as well as the population's perception of these policies. It was concluded that these bureaucrats have an inexpressive role in the operationalization and improvement of these policies when and if they are implemented, and that the population of these settlements is unaware of the benefits to which they are entitled within the axes of the PBQ.

Keywords: Brazil Quilombola Program; quilombola social agenda; quilombola; bureaucracy; public policies.

\section{UN ESTUDIO SOBRE LA APLICACIÓN DEL PROGRAMA BRASIL QUILOMBOLA EN LOS PUEBLOS DE RIBEIRA Y TABACARIA, ALAGOAS}

RESUMEN

Diversos estudios sobre la aplicación de las políticas que componen el Programa Quilombola Brasil (PBQ) demuestran que el acceso de las comunidades a los recursos y beneficios de estas políticas es extremadamente restringido. También destacan la dificultad de comunicación entre los responsables de las políticas del Programa y sus comunidades destinatarias. Otros estudios destacan el desconocimiento de los miembros de la comunidad quilombola sobre las políticas del PBQ, lo que dificulta la reivindicación de los derechos garantizados por este programa. Frente a este escenario, este artículo analiza si las políticas relacionadas con el PBQ fueron implementadas en dos comunidades quilombolas del estado de Alagoas y cuál fue el papel de los burócratas en estos procesos. A través de una investigación de campo y de entrevistas con burócratas y gestores de los departamentos responsables de la implementación y ejecución de este programa en los municipios, se trazó un mapa de las políticas dentro de los ejes que componen el PBQ y se analizó el papel de estos burócratas en la operacionalización y reajuste de estas políticas, así como la percepción de la población sobre estas políticas. Se concluyó que estos burócratas tienen un papel casi inexistente en la operacionalización y mejora de estas políticas cuando y si se implementan, y que la población de estos asentamientos no es consciente de los beneficios a los que tienen derecho dentro de los ejes del PBQ.

Palabras clave: Programa Quilombola Brasil; agenda social quilombola; quilombolas; burocracia; políticas públicas. 


\section{INTRODUÇÃO}

Em um panorama histórico marcado pela exclusão e pelo isolamento, as comunidades quilombolas no Brasil obtiveram, com a promulgação da Constituição Federal de 1988, o reconhecimento de sua importância na formação do patrimônio cultural brasileiro, bem como lhes foi assegurada a possibilidade de emissão dos títulos de posse das terras que ocupam. Todavia, a situação de vulnerabilidade ainda é uma constante no cotidiano dos remanescentes quilombolas porquanto muitas destas comunidades não têm acesso a seus direitos mais básicos. Isso se deve, entre outras coisas, ao fato de o artigo 68 do Ato das Disposições Constitucionais Transitórias (ADCT), que assegura o direito à terra às comunidades quilombolas, possuir uma redação curta e que carece de definições: "Art. 68. Aos remanescentes das comunidades dos quilombos que estejam ocupando suas terras é reconhecida a propriedade definitiva, devendo o Estado emitir-lhes os títulos respectivos" (Brasil 1988).

Este texto tão sucinto gerou uma disputa entre quilombolas e proprietários de terra em torno da definição do que fosse compreendido por "remanescentes das comunidades dos quilombos". Desde a promulgação da Constituição de 1988 até o início da década de 2000, um amplo debate nacional - envolvendo o Ministério Público Federal (MPF), antropólogos, geógrafos, historiadores e advogados
- foi feito em torno deste conceito. Em novembro de 2000, a Associação Brasileira de Antropologia (ABA) organizou, na Universidade Federal de Santa Catarina, uma oficina sobre laudos antropológicos cujas discussões e resultados foram publicados em Leite (2005). Houve um processo de ressignificação, no qual quilombo deixou de ser definido como um local distante, recôndito, onde se reuniam negros fugidos da escravidão, para ser definido como um local onde predominam populações afrodescendentes, habitado por remanescentes há várias gerações, onde estes se reproduzem social, econômica e culturalmente, tendo por base o uso comunitário da terra, de onde o núcleo familiar pratica agricultura de subsistência (Almeida 2002).

Toda essa discussão se cristaliza no Decreto $n$. 4.887, de 20 de novembro de 2003, que regulamentou o procedimento para identificação, reconhecimento, delimitação, demarcação e titulação das terras ocupadas por remanescentes das comunidades dos quilombos de que trata o art. 68 do Ato das Disposições Constitucionais Transitórias (Brasil 2003). Este artigo determina que:

Consideram-se remanescentes das
comunidades dos quilombos, para
os fins deste Decreto, os grupos
étnico-raciais, segundo critérios
de autoatribuição, com trajetória
histórica própria, dotados de relações
territoriais específicas, com presunção
de ancestralidade negra relacionada
com a resistência à opressão histórica
sofrida (Brasil 2003).

Consideram-se remanescentes das comunidades dos quilombos, para os fins deste Decreto, os grupos terios de ancestralidade negra relacionada sofrida (Brasil 2003). 
Como consequência de todo este debate, o Governo Federal lançou, em 12 de março de 2004, o Programa Brasil Quilombola (PBQ), “com o objetivo de consolidar os marcos da política de Estado para as áreas quilombolas” (SEPPIR 2004), visando desenvolver políticas que, mesmo que universais, possuam um caráter específico para a destinação às comunidades quilombolas, de acordo com as suas necessidades. O PBQ reconhece como “questão fundamental” (SEPPIR 2004:5) o acesso à terra, devido à concentração da propriedade fundiária, caracterizando a estrutura agrária do Brasil que exclui os moradores das comunidades tradicionais do acesso aos meios de reprodução. Portanto, "o Programa tem por finalidade coordenar as ações governamentais, através de articulações transversais, setoriais e interinstitucionais para as comunidades quilombolas, com ênfase na participação da sociedade civil" (SEPPIR 2004:6).

O PBQ é coordenado pela Secretaria Nacional de Políticas de Promoção da Igualdade Racial (SEPPIR) e integra as ações de vários ministérios ${ }^{1}$. A grande novidade trazida pelo Decreto n. 4.887/2003 e consolidada pelo PBQ foi uma abordagem das relações raciais no Brasil diferente daquela até então prevalecente nas ciências sociais brasileiras e nas políticas públicas destinadas à população negra. Antes de 2003, era explícita uma certa "afinidade eletiva" entre o "negro" e a "cultura" no trato das relações raciais pelo Estado brasileiro (Arruti 2009). Esta "afinidade" ainda era uma herança dos primeiros estudos sobre as populações negras brasileiras realizados por antropólogos como Nina Rodrigues, Arthur Ramos, Edison Carneiro, entre outros, interessados nas religiões de matriz africana, na música e no carnaval. A própria Constituição Brasileira de 1988, em seus artigos 215 e 216, repetia este "vício", ao tratar as relações raciais pelo viés da cultura, o que, na prática, se refletia em políticas de reconhecimento. Reconhecer é importante, mas não propõe nenhum tipo de mudança significativa na reprodução social das populações quilombolas.

O Decreto n. 4.887/2003 inclui, entre os seus objetivos, regularizar as questões fundiárias das comunidades quilombolas, acrescentando à pauta do reconhecimento a questão redistributiva. Ao fazer isso, o Estado reconhece a terra onde estão localizadas estas comunidades como o território onde elas se reproduzem social, cultural, política e economicamente, associando-as ao espaço no qual vivem. Pela primeira vez, o Estado brasileiro associa os aspectos culturais aos materiais de realização

1 Quando da sua implementação, onze ministérios tinham ações integradas no PBQ. Após 2016, várias mudanças foram realizadas, todas elas visando dificultar a implementação de políticas e ações públicas. Com a reforma estrutural realizada pelo governo, em 2019, a SEPPIR foi anexada ao Ministério das Mulheres, da Igualdade Racial e dos Direitos Humanos, o que enfraqueceu suas funções e prejudicou a implementação, o controle e a análise das políticas públicas voltadas para as comunidades tradicionais. 
da cultura. Segundo Arruti (2009:103-104), “os quilombos deixaram de ser um tema exclusivo da política cultural para serem reconhecidos como uma parcela da população nacional que deve ser atendida de forma diferenciada pelo conjunto de políticas públicas redistributivas". Este novo elemento trouxe para a questão quilombola uma forte resistência dos proprietários de terra, que se articularam para opor resistência ao Decreto n. 4.887/2003 e ao PBQ.

Em 2007, foi implementada a Agenda Social Quilombola (ASQ) (Decreto n. 6.261/2007), decorrente do PBQ e que está dividida em quatro eixos: acesso à terra; infraestrutura e qualidade de vida; inclusão produtiva e desenvolvimento local; direitos e cidadania (SEPPIR 2004).

\section{METODOLOGIA}

Com base nos eixos do PBQ, esta pesquisa analisou, através de metodologias qualitativas, o nível da implementação desse programa federal em duas comunidades quilombolas do estado de Alagoas: o povoado Ribeira, no município de Jacaré dos Homens, e o povoado Tabacaria, no município de Palmeira dos Índios. Foi realizado trabalho de campo com observação participante nessas duas comunidades, em momentos e períodos diferentes ${ }^{2}$. Em Ribeira, a pesquisa já dura três anos. Na Tabacaria, a mesma técnica foi utilizada durante um ano ${ }^{3}$. Em Ribeira, o trabalho de campo buscou observar o cotidiano desta comunidade, procurando entender como a comunidade se reproduz social, cultural e economicamente e como a certificação como comunidade quilombola modificou a qualidade de vida dos quilombolas.

Aplicou-se o Whoqol-Bref, instrumento de avaliação de qualidade de vida desenvolvido pela Organização Mundial de Saúde(OMS), para verificar a qualidade de vida da população das duas comunidades quilombolas analisadas. O objetivo foi verificar - antes de analisar a implantação dos programas do PBQ nessas duas comunidades - o possível impacto em termos de saúde do alto ou baixo nível de implementação desses programas governamentais.

Em Ribeira, foi aplicado o Whoqol-Bref a uma pessoa adulta de cada uma das 65 moradias da comunidade. Em Tabacaria, devido ao tempo mais curto, foram aplicados 42 questionários, sendo privilegiada uma pessoa adulta de lares diferentes que se encontrava em sua residência nos dias em que os pesquisadores lá estiveram.

2 Esta pesquisa foi aprovada pelo Comitê de Ética em Pesquisa da Faculdade Tiradentes (hoje, Centro Universitário Tiradentes - UNIT/AL), pelo parecer n. 1.313.381, emitido em 9 de novembro de 2015.

3 A pesquisa na Tabacaria foi realizada em período mais curto porque foi efetivada no processo de coleta de dados para compor os dados de uma dissertação de mestrado sobre a implementação do eixo sobre desenvolvimento econômico e social do PBQ. 


\section{RESULTADOS}

O objetivo original para aplicação do questionário foi identificar como os moradores dessas comunidades avaliavam sua qualidade de vida frente à implantação das políticas públicas.

Os resultados dos questionários mostraram que mais de $90 \%$ dos entrevistados, em ambos os quilombos, consideram que gozam de boa qualidade de vida. Com a aplicação do WhoqolBref, os pesquisadores puderam constatar que não há uma clara relação entre implementação de políticas públicas e qualidade de vida, bem como que a qualidade de vida não é percebida por estes quilombolas como uma consequência da implementação de políticas públicas.

No que concerne ao suporte social, os respondentes demonstraram pouco conhecimento em termos de políticas e direitos. Nas visitas e nas estadas em campo, os pesquisadores verificaram que, tanto nessas comunidades quanto entre os gestores dos órgãos municipais, as ações e os programas contidos no PBQ são quase desconhecidos. Estas comunidades quilombolas sofrem de um problema comum às outras Brasil afora, uma vulnerabilidade social decorrente da ausência de serviços essenciais, como saneamento básico, educação e saúde de qualidade. Nestes três “campos”, não existem políticas e ações específicas para as populações quilombolas (Arruti 2009; Mello et al. 2014). As ações desenvolvidas nestas comunidades, quando o são, são frutos de políticas e ações mais gerais voltadas para a população negra no Brasil, e carecem de uma especificidade própria aos quilombolas.

Buscando compreender as particularidades da vulnerabilidade de Ribeira e Tabacaria, mapeouse as políticas implementadas e entrevistou-se gestores locais e a burocracia local. Concluiu-se que poucas políticas do $\mathrm{PBQ}$ foram implementadas e que os burocratas têm um papel quase nulo na operacionalização, na rotinização e na melhora daquelas que foram implementadas.

Em relação à investigação relacionada especificamente ao $\mathrm{PBQ}$, o artigo dividese em três partes. Na primeira, discorre-se sobre as políticas e suas burocracias. Após isso, apresenta-se os dois povoados - Ribeira e Tabacaria - para, então, na última parte, expor e analisar a atuação dos burocratas responsáveis pela implementação do PBQ nas duas comunidades quilombolas. Demonstrase que, para que a garantia constitucional da manutenção da identidade quilombola esteja, de fato, assegurada, as políticas públicas referenciadas pelos eixos da PBQ precisam de maior efetividade em sua implementação. 


\section{POLÍTICAS E BUROCRACIAS NO PROGRAMA BRASIL QUILOMBOLA}

Estudos sobre a implementação das ações e das políticas que compõem o PBQ demonstram que o acesso pelas comunidades aos recursos nelas previstos e aos seus benefícios é extremamente restrito. Destacam também a dificuldade de comunicação entre os executores dessas políticas e as comunidades-alvo (Vieira 2015; Souza \& Brandão 2017). Outros estudos demarcam a questão da falta de conhecimento dos membros das comunidades quilombolas acerca das políticas do $\mathrm{PBQ}$, o que dificulta a reivindicação e a implementação dos direitos nelas contidos (Barbosa et al. 2016; Vieira 2015). Analisando dados referentes ao PBQ no estado do Maranhão, Teixeira (2017) tece uma crítica contumaz a este programa. Segundo este autor, o PBQ, que tinha como objetivo operar "como um dispositivo de governo que inclui simbolicamente as comunidades quilombolas, aparentemente atendendo demandas de movimentos sociais" (Teixeira 2017:1), com a falta de regulação orçamentária e os cortes em seu orçamento, ocorridos, sobretudo, no governo Dilma Rousseff, acabou por excluir essas comunidades das políticas públicas específicas voltadas para elas, bem como daquelas mais gerais, que têm como público-alvo a população afrodescendente, das quais são excluídas por contarem com políticas específicas que, contudo, como visto anteriormente, têm sua implementação entravada.

Barbosa et al. (2016), na mesma direção, levantam alguns elementos que entravam na implementação do PBQ. Em primeiro lugar, as "circunstâncias locais": mesmo após a execução do $\mathrm{PBQ}$, agentes locais "que são contrários à titulação das comunidades continuam tentando acionar mecanismos que impeçam ou pelo menos dificultem a implementação do programa. Isso certamente não foi previsto na etapa de formulação [do PBQ]" (Barbosa et al. 2016:15). Outros entraves listados são a falta de recursos humanos e materiais no Instituto Nacional de Colonização e Reforma Agrária (INCRA), responsável pela demarcação, "desintrusão" e titulação das terras quilombolas, e a dificuldade de coordenação de todo o corpo burocrático responsável pelo $\mathrm{PBQ}$, que envolve vários ministérios e agências governamentais. Estas autoras levantam uma questão interessante, que é a morosidade do Estado brasileiro em reconhecer aqueles que se autodefinem como quilombolas, exigindo laudos antropológicos e históricos que legitimem os pleitos desses sujeitos sociais, muito embora o Decreto n. 4.887/2003 afirme que basta a autodefinição da própria comunidade para que esta esteja em condições de usufruir de todos os direitos que lhes são previstos. O PBQ remete à discussão entre regionalização, coordenação e 
complexidade das políticas públicas. É um conjunto de ações descentralizadas entre as instituições federais, estaduais, municipais e organizações da sociedade civil, coordenadas no âmbito da SEPPIR (Rodrigues 2010).

O Decreto n. 4.887/2003, buscando enfatizar a democratização da aplicação das políticas públicas voltadas para os quilombolas, define as competências da federação, dos estados e dos municípios na implementação de políticas e ações para as comunidades quilombolas, por meio de um Comitê Gestor, do qual fazem parte representantes das comunidades quilombolas. O Governo Federal incentivava também a formação de comitês estaduais que envolvessem representantes do estado e dos municípios onde existam quilombolas, além dos representantes regionais de órgãos federais. Desta maneira, o Governo Federal buscava democratizar as decisões sobre a implementação dessas políticas. Arruti (2009:107) aponta dois problemas para que esta municipalização funcione: 1) é preciso uma postura favorável do executivo municipal, o que, na maioria dos casos, não ocorre, visto que os interesses políticos locais interferem negativamente na implementação das políticas voltadas para os quilombolas; 2) é preciso "uma organização quilombola informada e com livre trânsito entre as instâncias oficiais" (Arruti 2009:107).
Como bem abordam Mello et al. (2014), as dificuldades colocadas pelas administrações municipais já começam a partir de algo tão simples como preencher corretamente as informações do CadÚnico, que, desde 2010, possui "um campo específico para marcação de família cadastrada como quilombola" (Mello et al. 2014:198). E mesmo quando este campo é corretamente preenchido e o Governo Federal envia a verba correspondente para o município, não há garantia de que a administração municipal irá utilizá-la para seus fins específicos.

As dificuldades e os obstáculos encontrados para a implementação de políticas, ações e programas previstos no PBQ podem ser exemplificados pelos dados que ilustram a questão quilombola no estado de Alagoas. Existem sessenta e oito comunidades quilombolas certificadas em Alagoas, espalhadas por 35 municípios. As primeiras foram certificadas no dia 19 de abril de 2005. A última foi certificada em 7 de fevereiro de 2011. Dessas sessenta e oito comunidades já certificadas, apenas uma, povoado Tabacaria, conseguiu a titularidade das terras onde se encontra.

Além dos eixos referentes ao acesso à terra e à infraestrutura, alguns eixos e diretrizes do $\mathrm{PBQ}$ concernem ao fortalecimento organizacional das comunidades quilombolas, e assim entra 
[...] em foco a própria elaboração e gestão das políticas públicas: (c) o incentivo aos governos estaduais e municipais na promoção do acesso de quilombolas às políticas públicas, com ênfase na regularização da posse da terra e no estímulo ao desenvolvimento sustentável em seus territórios; (d) a proposição de um modelo de gestão destas políticas que preserve a igualdade de oportunidade e de tratamento dado a estas comunidades, em comparação com os demais públicos; (e) o estímulo ao protagonismo dos quilombolas em todo processo de decisão, fortalecendo sua identidade cultural e política; e, finalmente, (f) a garantia dos direitos sociais e do acesso à rede de proteção social (Arruti 2010:16).

O PBQ, em seus quatro eixos, engloba uma série de políticas, programas como Minha Casa Minha Vida, Bolsa Família, Saneamento Rural, Saúde da Família e Saúde Bucal, Luz para Todos, Água para Todos, Educação de Jovens e Adultos (EJA), distribuição de cestas básicas, entre outros. Desde sua formulação, muitos problemas vêm sendo colocados buscando impedir ou retardar a implementação do $\mathrm{PBQ}$, trazidos por atores contrários a essa política, sobretudo no que concerne aos processos de titulação (Barbosa et al. 2016). Em relação à política fundiária, a

Burocracia envolvida no acesso à terra pelos quilombolas não é exclusiva ao $\mathrm{PBQ}$, atingindo as mais diversas esferas do Estado brasileiro, podendo ser considerada um fator cultural presente na visão de agentes formuladores e implementadores (Barbosa et al. 2016:18).
A ausência da burocracia de ponta, assim como daquela de médio escalão, pode ser uma das explicações para as dificuldades na implementação do programa. A burocracia no nível de rua (streetlevel bureaucracy) é aquela que lida com a política em seu sentido operacional, na ponta, na interação direta com o público-alvo das políticas (Lipsky 1980). Conforme Lipsky (2019:37), os

[...] típicos burocratas de nível de rua
são os professores, policias e outros
funcionários responsáveis pela aplicação
da lei, os assistentes sociais, os juízes,
os defensores públicos e outros oficiais
dos tribunais, trabalhadores da saúde
e muitos outros funcionários públicos
que concedem acesso a programas
governamentais e possibilitam a
prestação de serviços dentro deles.

São, portanto, aqueles atores que detêm conhecimento privilegiado no processo de implementação e operacionalização das políticas e "introduzem aos cidadãos as possíveis expectativas a respeito dos serviços públicos e seu lugar na comunidade política" (Lipsky 2019:39).

No caso das duas comunidades quilombolas aqui analisadas, pode-se assim considerar os agentes de saúde, os assistentes sociais, entre outros, envolvidos na implementação de políticas como o Programa Bolsa Família, Saúde da Família etc. Conforme afirma Lipsky (2019), a importância desse tipo de burocracia 
é aproximar as políticas públicas dos cidadãos, em especial a população mais carente, uma vez que, "quanto mais pobres os cidadãos, maior a influência que os burocratas de nível de rua tendem a ter sobre eles” (Lipsky 2019:43).

Os burocratas de médio escalão são aqueles que se situam entre o alto escalão e a burocracia de ponta, entre a formulação e a execução de políticas, como assessores, diretores, coordenadores, secretários, chefes de gabinete, entre outras funções. Eles atuam com mais discricionariedade em relação à burocracia de ponta. Eles têm, em tese, mais liberdade, mesmo que limitada, para perceber e propor mudanças em algum aspecto da política, em seu processo de implementação. $\mathrm{Na}$ perspectiva bottom-up, são os atores que podem, em contato com os burocratas do nível de rua, constatar os problemas de implementação e modificar a política formulada no topo (Monteiro 2016). Isso ocorre porque essa burocracia se distingue da do nível de rua pela "autonomia em termos de recursos públicos disponíveis para a implementação de ações em políticas públicas" (Oliveira \& Abrúcio 2018:212-213). Sua característica fundamental é a de promover "o diálogo entre as necessidades do público que atende com as prioridades estabelecidas pelo alto escalão"
(Oliveira \& Abrúcio 2018:212).

A burocracia de alto escalão, mesmo na política local, define-se não pelo compromisso com a organização pública a que está vinculada, ou com a política pública envolvida, mas pela carreira, seja ela burocrática ou política. A burocracia de alto escalão é composta de cargos por indicação, participa da definição das diretrizes gerais do serviço ou política pública oferecida, coordena programas concomitantemente com outros, indica novas diretrizes para as políticas/programas e, principalmente, lida diretamente com os recursos (Oliveira \& Abrúcio 2018). O alto escalão lida com o PBQ com certa discricionariedade ilimitada, ao contrário das outras burocracias - nível de rua e médio - e, embora não tenha poder de veto ou discricionariedade ilimitada na execução dos programas, tem um papel que impacta o nível de implementação das políticas e sua avaliação. A ausência ou descoordenação entre as burocracias pode indicar sérios problemas de implementação, em especial na relação de assimetria de informação entre burocrata de nível de rua/ usuário, burocrata de nível de rua/supervisor, burocrata de nível de rua/político (Ferreira \& Medeiros 2016). 


\section{AS COMUNIDADES QUILOMBOLAS DOS POVOADOS RIBEIRA E TABACARIA}

O quilombo povoado Ribeira localiza-se no município de Jacaré dos Homens, no sertão semiárido alagoano, mais precisamente na região conhecida como Bacia Leiteira. Seu nome advém de sua localização, às margens do riacho Jacaré, rio temporário que corta todo o município de Jacaré dos Homens e desemboca no rio São Francisco, já no município de Pão de Açúcar. Neste povoado, moram quarenta e duas famílias ${ }^{4}$, com cerca de 150 pessoas. Foi certificado como comunidade remanescente de quilombo em 7 de fevereiro de 2011, sendo a última comunidade remanescente de quilombo certificada em Alagoas.

A reprodução social eeconômica do povoado Ribeira, em seu microespaço, está baseada na agropecuária. A economia local é sustentada pela agricultura familiar, que produz, em pequena quantidade, feijão, mandioca e milho, quando o regime de chuvas assim o permite. Alguns quilombolas possuem umas poucas cabeças de gado bovino e caprino leiteiro, cuja produção, associada ao baixo preço do litro de leite in natura, é insuficiente para garantir a sobrevivência das famílias. Devido a isso, as cestas básicas distribuídas pelos programas sociais do Governo Federal e o Bolsa Família desempenham papel fundamental no processo de reprodutibilidade social dos moradores deste território.
Nesta comunidade, não há conflito de terra com fazendeiros. Alguns quilombolas mais idosos possuem pequenas propriedades, herdadas de seus ascendentes consanguíneos, um casal que adquiriu a propriedade da terra na virada do século XIX para o século XX. Hoje, seus netos e bisnetos são os donos da terra. Contudo, existe latente conflito entre os moradores, porque aqueles que possuem pequenas propriedades as arrendam, parcial ou integralmente, para aqueles que não possuem terra, auferindo renda desta maneira, ao mesmo tempo que excluem os parentes mais jovens do acesso à terra.

Ribeira possui rede de distribuição de água instalada pela Companhia de Abastecimento d'Água eSaneamento do Estado de Alagoas (Casal), mas aquilo que deveria ser uma solução tornou-se um problema. A distribuição de água pela Casal é esporádica e a comunidade sofre com o desabastecimento, tendo que recorrer, frequentemente, ao abastecimento por caminhões pipa. Os moradores de Ribeira não são atendidos pelo Programa Nacional de Universalização do Acesso e Uso da Água (Água para Todos), implementado e administrado pelo Ministério da Integração Nacional, que exclui de seu público-alvo populações servidas por rede que assegure o abastecimento regular de água por uma companhia de saneamento. A água da Casal não é fornecida regularmente, mas a rede encontra-se

4 Dados resultantes da aplicação de uma planilha que visava levantar informações sobre parentesco e renda junto às famílias do povoado Ribeira. Esta planilha foi aplicada em todas as residências existentes neste quilombo. 
instalada, impedindo que o programa citado atenda à população local.

As redes de água e de energia elétrica foram instaladas na comunidade após a implementação do PBQ, em 2004, antes, entretanto, da certificação desta comunidade pela Fundação Cultural Palmares (FCP). Os moradores não relacionam a chegada de ambas as redes na comunidade às ações do PBQ, muito embora o fornecimento de água, esgoto e energia elétrica seja ação prevista neste programa.

O povoado Tabacaria, por sua vez, está situado na zona rural do município de Palmeira dos Índios, no agreste alagoano. Foi certificado em 30 de setembro de 2005, constituindo-se como uma das primeiras comunidades remanescente de quilombo certificadas em Alagoas. Nele, moram noventa e duas famílias (ITERAL s/d), com cerca de 290 pessoas. Este povoado localiza-se em uma região onde existe um índice pluviométrico maior do que no povoado Ribeira, mas a falta d'água também é um problema para seus moradores.

Segundo alguns relatos obtidos por meio de conversa informal com lideranças comunitárias, moradores desta comunidade trabalhavam para fazendeiros locais e plantavam fumo para seu próprio consumo e para o consumo das cidades circunvizinhas. Havia um cigarro artesanal, confeccionado pela comunidade, ao qual chamavam de "tabaco", por isso a comunidade foi identificada como Tabacaria.

Tabacaria viveu da "boa vontade" dos fazendeiros, tidos como donos das terras onde a comunidade se estabeleceu. Como reconhecimento em 2005, a memória coletiva da comunidade foi resgatada, e o espaço geográfico passou a representar um local de luta por direitos negados historicamente. Entre as comunidades remanescentes de quilombos no estado de Alagoas, Tabacaria é aquela que possui um dos maiores níveis de articulação política e de consolidação do processo de posse da terra, e é a única que alcançou a conclusão do processo fundiário até o presente, possuindo a titularidade de 410 hectares. A titulação de suas terras ocorreu em cerimônia realizada em 20 de novembro de 2016. Contudo, apesar de titulada, esta comunidade ainda se encontra desassistida de políticas públicas voltadas para a saúde, assistência técnica e social e de fomento ao desenvolvimento produtivo, situação que a impede de se desenvolver produtivamente.

Tal situação coloca em risco as conquistas efetivadas pelo reconhecimento da existência da comunidade e pela concessão do título de propriedade da terra, sem proporcionar aos camponeses acesso a financiamento de sementes e insumos para a exploração de suas terras, o que não permite que estes possam plantar e extrair da terra o suficiente para o sustento de suas famílias. Sendo assim, a propriedade continua economicamente improdutiva. Desta maneira, apesar de possuir terra suficiente para sua reprodução social, Tabacaria é um dos quilombos mais pobres de Alagoas. Até muito recentemente, seus moradores habitavam casas de 
pau a pique ou tendas de lona, que só agora vêm sendo substituídas por casas de alvenaria, do programa Minha Casa, Minha Vida, do Governo Federal. Contudo, não foram construídas casas em número suficiente para abrigar todas as famílias que moram no povoado.

\section{SOBRE A PERCEPÇÃO DO PBQ EM RIBEIRA E EM TABACARIA}

De acordo com o relatório da Secretaria de Estado do Planejamento, Gestão e Patrimônio (SEPLAG 2015), a situação de vulnerabilidade dos quilombolas no estado de Alagoas é evidente: 86\% desta população recebem os benefícios do Programa Bolsa Família e 75\% estão dentro da linha de extrema pobreza. A maioria vive da agricultura familiar de subsistência.

Quando analisamos a implementação e a execução de políticas públicas em comunidades quilombolas, constata-se dois vieses importantes: 1)a "percepção" que as comunidades têm a respeito dessas políticas - muitas vezes, existem algumas políticas implementadas, mas os quilombolas não percebem seus efeitos como consequência de políticas públicas -;2) a implementação, de fato, das medidas previstas.

No que concerne às duas comunidades, os programas mais "perceptíveis" são aqueles cujos resultados se concretizam na satisfação de necessidades mais imediatas e prementes, como a renda familiar e a alimentação regular. Devido a isso, os dois programas mais identificados e citados, quando se pergunta sobre políticas públicas, são o Bolsa Família e a distribuição de cestas básicas pela Companhia Nacional de Abastecimento (CONAB).

No povoado Ribeira, por exemplo, quando se pergunta aos moradores o que mudou após a certificação da comunidade enquanto quilombola, a resposta é, na grande maioria das vezes: "nada, não mudou nada”. Quando são feitas perguntas mais específicas sobre ações do PBQ - "vocês pagam menos pelo uso da energia elétrica?" (ação prevista no programa Luz para Todos) -, a resposta já pode trazer uma contextualização: "uns pagam, outros não”. A percepção ou a falta de percepção dos quilombolas sobre as ações e políticas públicas resulta de uma enorme dificuldade que o Governo Federal, elaborador do PBQ e da ASQ, e seus parceiros nos estados e municípios têm de se comunicar com o público-alvo dessas políticas. Resulta também do desconhecimento e, muitas vezes, da falta de interesse dos gestores municipais.

O eixo central da questão quilombola é o acesso à terra. Não raro, a terra reivindicada pelas comunidades quilombolas também é cobiçada pelas oligarquias locais, que procuram dificultar ao máximo o acesso dos quilombolas aos programas que os tornem independentes da estrutura de compadrio político local. Outro fator que influencia na implementação da ASQ é o próprio desconhecimento dos quilombolas 
daquilo que nela está previsto.

Ribeira conta com uma infraestrutura melhor do que Tabacaria. Em Ribeira, existe apenas uma casa de taipa; todas as outras, novas, são em alvenaria. Algumas contam com fossa séptica. Como mencionado, existe tubulação para o fornecimento de água tratada, embora isso seja irregular. Contudo, os quilombolas desconhecem o Selo Quilombola e o Programa de Aquisição de Alimentos (PAA). O posto de saúde de apoio que existia neste povoado foi fechado, não foi implementado o programa de geração de renda, nem de educação quilombola, além de outras ações previstas na ASQ.

No povoado Tabacaria, a situação é muito mais precária. Segundo o levantamento feito pela Secretaria Municipal de Assistência Social (SMAS) da Prefeitura de Palmeira dos Índios, existiam, até o ano de 2016, 97 moradias nesta comunidade, sendo 51 de alvenaria, 31 de taipa e 15 de lona (SMAS 2016). A comunidade recebeu o programa Minha Casa, Minha Vida, que construiu as casas em alvenaria. Outras encontram-se em fase de construção, mas nem todos os moradores receberão casas novas. Não existe rede de água e esgoto e somente três casas "tinham eletricidade instalada pelo órgão responsável, as outras são instalações improvisadas" (SMAS 2016:9).

Entre os moradores em idade ativa, o desemprego é grande. $\mathrm{O}$ mesmo ocorre em Ribeira. $\mathrm{O}$ desemprego é maior entre os jovens que não querem seguir a profissão dos pais - agricultor -, porque não a identificam como uma profissão valorizada no mercado de trabalho e que permita alcançar o que eles consideram como boa qualidade de vida.

Não há escola em Tabacaria. No que concerne à educação, "nesta comunidade funcionam algumas salas de Educação de Jovens e Adultos (EJA), além da creche concentrando crianças a partir dos seis meses" (SMAS 2016:12). As crianças que precisam frequentar o ensino fundamental deslocam-se até a escola mais próxima, localizada em sítio nas adjacências.

A economia local está baseada na agricultura de subsistência, destacando-se as culturas da batata, da macaxeira, do milho e do feijão. Contudo, o regime irregular de chuvas e o baixo uso de insumos e técnicas agrícolas modernas fazem com que seja baixa a produtividade.

A responsabilidade pela implementação das políticas públicas previstas na ASQ junto aos quilombolas é, sobretudo, dos agentes públicos pertencentes à estrutura municipal. Em entrevistas realizadas para a pesquisa, percebemos que estes agentes públicos não são adequadamente treinados para conhecer, implementar, executar e avaliar estas políticas e ações, e que as prefeituras municipais não possuem estrutura voltada para a efetivação dessas políticas e ações. 


\section{A PERCEPÇÃO DOS BUROCRATAS}

\section{EM RELAÇÃO À IMPLEMENTAÇÃO DAS}

\section{POLÍTICAS PREVISTAS NO PBQ E NA ASQ}

Jacaré dos Homens, onde está localizado o povoado Ribeira, é um município pequeno. No último censo realizado pelo Instituto Brasileiro de Geografia e Estatística (IBGE), moravam, neste município, 5.413 habitantes, com uma densidade demográfica de 38,03 hab./ $\mathrm{km}^{2}$. O IBGE estima que a população, em 2018, seria de 5.288 habitantes, menos 125 habitantes (tendo perdido cerca de 2,1\% do total de sua população em oito anos), mostrando que este município não consegue reter a população (IBGE 2011). Quase a integralidade de seu corpo de funcionários é formado por contratados: poucos são concursados. Este expediente é muito utilizado em pequenas cidades do interior, de maneira a economizar o gasto com a organização de concursos públicos e permitir ao gestor municipal colocar seus apadrinhados na gestão pública. Para buscar entender as dificuldades para a implementação do PBQ e da ASQ, foram entrevistados gestores públicos e agentes responsáveis pela execução dos programas nas duas cidades.

Em Jacaré dos Homens, foram entrevistados gestores municipais de primeiro escalão. Ao se perguntar a um deles como avaliava a eficácia de políticas, programas e ações públicas, a resposta recebida foi: "ótima". Ao se perguntar especificamente como as políticas voltadas para a população quilombola são implementadas no município, a resposta foi de que não estão implementadas em Jacaré dos Homens políticas específicas para as populações quilombolas. Ao se perguntar sobre quais as dificuldades encontradas para implementar este tipo de política, a informação que recebemos foi de que falta pessoal capacitado para desenvolver tais funções. O entrevistado salientou que foi procurado por "profissionais" da Universidade Federal de Alagoas (UFAL), capacitados neste tipo de política pública, mas não deu mais detalhes.

O gestor da área de cultura respondeu que não tem nenhuma política, programa ou ação pública voltada para as comunidades quilombolas sendo desenvolvidas, implementadas ou executadas por sua secretaria. Perguntado sobre o porquê de não existirem estas políticas específicas, ele respondeu que não são prioritárias para o município.

O secretário de infraestrutura e meio ambiente alegou desconhecer a existência de tais políticas, programas e ações. Declarou como dificuldade para sua implementação a necessidade de possuir um conhecimento jurídico específico e que teria dificuldades para implementar essas políticas por falta de orçamento específico.

O secretário de educação respondeu às mesmas perguntas que não executa políticas específicas para as comunidades quilombolas porque procura 
dar tratamento de maneira igualitária para todo e qualquer cidadão do município. Devido a isso, sua secretaria não implementa nem executa nenhum tipo de política específica para as comunidades quilombolas. Alegou que os problemas que encontra para implementar políticas, programas e ações públicas se devem à dificuldade com capacitação e entendimento de políticas e leis específicas. Soma-se, ainda, a dificuldade de relacionamento com o Governo Federal, tornando complexa a avaliação das políticas públicas.

O secretário de finanças informou que não há verbas específicas destinadas às comunidades quilombolas e que sua secretaria não é responsável por nenhuma ação voltada para esta população. Como dificuldades encontradas para implementar estas políticas, mencionou a não arrecadação de subsídios governamentais destinados diretamente aos quilombos e que não conhece a existência de verbas específicas para estas comunidades.

Por fim, o secretário de saúde falou que procura tratar todos os cidadãos de maneira igualitária e que não desenvolve políticas, programas e ações específicas para os quilombolas. Alegou que a dificuldade de comunicação junto à população quilombola e a falta de conhecimento acerca de diretrizes concernentes às comunidades quilombolas dificultam a implementação desse tipo de política, mas afirmou que as políticas públicas sob sua responsabilidade são avaliadas com o conjunto de toda a população de Jacaré dos Homens.

As respostas ora destacadas podem ser englobadas em algumas abordagens básicas: a primeira é a "qualificação", segundo a qual falta pessoal devidamente capacitado para implementar e executar as políticas previstas no PBQ. Nenhum dos gestores que abordou esta questão, contudo, revelou algum tipo de iniciativa que procurasse providenciar capacitação para os agentes públicos. O prefeito mencionou uma aproximação com a UFAL, mas não deu mais detalhes. Outra abordagem, que poderíamos chamar de "democrática", afirma que estas políticas não são implementadas para não privilegiar um segmento populacional específico, em detrimento da maioria, desconhecendo princípios básicos das políticas de reparação, ação afirmativa e da discriminação positiva (Moehlecke 2002; Campos \& Feres Júnior 2014; Feres Júnior et al. 2012), que reconhecem as políticas previstas na ASQ como necessárias para reparar uma dívida social da sociedade brasileira contra a população quilombola e todos os afrodescendentes no Brasil. Por fim, o terceiro eixo, "desconhecimento", no qual os gestores alegam não saber da existência destas políticas.

Esse cenário sinaliza a falta de preparo dos gestores municipais para o exercício das funções 
públicas que, somada ao desconhecimento dos quilombolas sobre a ASQ, contribui para a não implementação das políticas previstas no PBQ. Sinaliza também a falta de comunicação do Governo Federal, formulador do PBQ e da ASQ, com os gestores municipais responsáveis por fazer com que o que está previsto nestas duas ações chegue até seu público-alvo. Por fim, indica também que não existem agentes públicos específicos responsáveis por implementar essas políticas junto às populações quilombolas.

Palmeira dos Índios, onde se localiza o povoado Tabacaria, é um município maior do que Jacaré dos Homens e conta com uma estrutura de funcionários mais reforçada. A pesquisa entrevistou pessoas que desempenham funções de burocratas de nível de rua também junto à comunidade da Tabacaria. Estes entrevistados responderam às mesmas perguntas feitas em Jacaré dos Homens. Sobre quais políticas, programas e ações públicas específicas para as comunidades estão implementadas em Palmeiras dos Índios, a primeira entrevistada respondeu não existir um direcionamento específico em sua função para a comunidade quilombola e sua atuação na comunidade ocorre quando sua secretaria realiza alguma ação pontual. Segundo ela, na Tabacaria, os quilombolas contam com o apoio do Bolsa Família, e as gestantes desta comunidade recebem uma cesta nutricional por mês. Ela prossegue informando que faltam estruturas permanentes (salas, galpões etc.), onde ações de cunho permanente possam ser desenvolvidas. Não existem profissionais qualificados e recursos suficientes. Tabacaria fica em uma pequena serra e a estrada de acesso não é pavimentada, o que dificulta o acesso à região, sobretudo na época em que chove forte. No que concerne à avaliação das políticas públicas, evidencia-se que faltam planejamento, cumprimento dos prazos de entrega de relatórios, controle social e instrumentos desenvolvidos para a avaliação.

A segunda entrevistada informou que funcionam, na Tabacaria, o Programa do Leite ${ }^{5}$, programa estadual, mas que coaduna como ação do eixo três do PBQ, e o Programa de Atendimento Domiciliar $(\mathrm{PAD})^{6}$. Contudo, é preciso melhorar o acompanhamento das famílias vulneráveis nos aspectos nutricionais e sociais. Existe uma diretoria e coordenação deste programa que utiliza recursos dos governos federal, estadual e municipal. A população vulnerável é cadastrada e a distribuição

5 O Programa do Leite, em Alagoas, foi criado em 2002 e beneficia mais de 53 mil famílias que vivem abaixo da linha da pobreza nos 102 municípios do estado. Cada família assistida recebe um litro de leite por dia.

6 O Programa de Atendimento Domiciliar é realizado por uma equipe multidisciplinar, composta por médicos, enfermeiros, técnicos em enfermagem e nutricionistas, que visitam pessoas doentes, sobretudo com doenças crônicas, em seus domicílios. 
ocorre no próprio povoado. A maior dificuldade encontrada é o reduzido tamanho da equipe responsável pela parte referente à segurança alimentar. Embora previsto no Plano Municipal de Assistência Social da prefeitura de Palmeira dos Índios, ainda não foram elaborados diagnósticos destas políticas públicas.

A terceira e última entrevistada informou que a totalidade da população do povoado Tabacaria é coberta pelo Programa Bolsa Família, que não é um programa específico do $\mathrm{PBQ}$, mas se insere como ação de seu eixo 3. Ela defende que haja maior interação dos responsáveis pelo Bolsa Família com a área da saúde e da educação. Segundo ela, o cadastro e a atualização do Bolsa Família neste povoado só são realizados quando sua secretaria organiza alguma ação itinerante, na qual esteja prevista uma ida ao quilombo, já que o município não possui nenhuma estrutura física na Tabacaria. As principais dificuldades encontradas são a ausência de estrutura física neste povoado, carência de recursos humanos e acesso dificultado pelas más condições de manutenção da estrada de acesso, além da ausência de vontade política para resolver os problemas.

Embora exista um corpo técnico que poderia trabalhar na implementação e na análise das ações previstas no PBQ, em Palmeira dos Índios, ele conta com efetivo em número insuficiente, que, juntamente com estrutura física e dificuldade de acesso, contribuem para a baixa cobertura do PBQ na Tabacaria.

Comparando-se as estruturas municipais existentes em Jacaré dos Homens e em Palmeira dos Índios, no primeiro munícipio não existe nenhum tipo de burocrata, seja de nível de rua ou de gabinete, que se ocupe dos quilombos. Em Palmeira dos Índios, a burocracia de nível de rua que se ocupa da Tabacaria o faz dentro de suas funções cotidianas, não sendo uma burocracia específica para atender às demandas quilombolas.

\section{CONSIDERAÇÕES FINAIS}

Passados quinze anos da criação do PBQ, Ribeira e Tabacaria sofrem o impacto da implantação ineficiente desse programa. Tanto os quilombolas quanto as administrações municipais dos municípios onde se localizam estes quilombos têm pouquíssimo conhecimento sobre os direitos por ele assegurados, as verbas disponíveis para as prefeituras aplicarem nessas comunidades e as obrigações que a burocracia municipal tem para como elas.

As comunidades remanescentes de quilombo contam com diversas políticas, programas $\mathrm{e}$ ações públicas voltadas para a resolução de seus problemas específicos. Embora possam 
ser melhoradas, estas contemplam as diferentes necessidades e carências mais comuns e presentes nas comunidades. A dificuldade em implementá-las e adequá-las mais precisamente às demandas de cada comunidade quilombola advém da falta de uma burocracia que fique responsável pela implementação e pela análise dessas ações. Esta ausência resulta de alguns fatores, tais como a falta ou descoordenação entre as burocracias - devido à assimetria de informação entre burocrata de nível de rua/ usuário, burocrata de nível de rua/supervisor, burocrata de nível de rua/político - e a falta de capacitação específica para lidar com o PBQ.

Os municípios onde se localizam as comunidades aqui analisadas não possuem orçamento e estrutura específica, além de conhecimento e capacitações e, muitas vezes, interesse das lideranças políticas locais, que permitam o bom funcionamento do PBQ. As lideranças políticas locais cobiçam as terras de Ribeira e Tabacaria e percebem a existência desses quilombos como uma quebra das relações de propriedade prevalecentes em Jacaré dos Homens e em Palmeira dos Índios.

A pesquisa identificou, como causa principal da implementação ineficiente do $\mathrm{PBQ}$, o desconhecimento das ações e das políticas que compõem este programa, bem como o despreparo dos gestores municipais no que concerne à demanda das verbas públicas para a implementação dessas políticas, decorrente, sobretudo, do desconhecimento da existência delas. Os próprios quilombolas desconhecem a maioria das ações previstas no PBQ e na ASQ e, dessa forma, não conseguem cobrar das burocracias municipais a plena implementação das políticas que lhes cabem, nem conseguem demandar assento nos Comitês Gestores municipais ou a sua formação nestes dois municípios, posto que estes comitês lá sequer existem.

Poderia se alcançar maior eficácia do PBQ e da ASQ se houvesse um corpo técnico, uma burocracia, que se responsabilizasse pela sua implementação e análise de sua aplicação. Esta burocracia poderia ser alocada sob a responsabilidade da SEPPIR (que já não existe mais) ou, talvez, do Ministério do Planejamento, ou de qualquer outro que os substituísse em suas funções, e seria contratada e capacitada para atuar, especificamente, na sua implementação.

\section{AGRADECIMENTOS}

Este artigo conta com dados vinculados à pesquisa "A reprodutibilidade sociocultural em uma comunidade remanescente de quilombos no estado de Alagoas", realizada com apoio do Edital Universal 01/2016 e do Edital n. 13/2016 - Apoio a Pesquisas - PPGs/Humanidades. 


\section{REFERÊNCIAS}

Almeida, A. W. B. 2002. Os quilombos e as novas etnias, in Quilombos: identidade étnica e territorialidade. Editado por Eliane Cantarino O’Dwyer, pp. 43-81. Rio de Janeiro: Editora FGV.

Arruti, J. M. A. 2009. Políticas públicas para quilombos: terra, saúde e educação, in Caminhos convergentes: Estado e sociedade na superação das desigualdades raciais no Brasil. Organizado por Marilene de Paula \& Rosana Heringer, pp. 75-110. Rio de Janeiro: Fundação Heinrich Boll/ActionAid.

Arruti, J. M. A. 2010. Notas sobre as iniciativas federais em educação no contexto das políticas públicas para quilombos, in Educação escolar quilombola: pilões, peneiras e conhecimento escolar. Editado por Secretaria de Estado da Educação, Superintendência da Educação, pp. 13-31. Curitiba: SEED.

Barbosa, M. P., L. A. M. Braga, e C. T. Rodrigues. 2016. Programa Brasil Quilombola: análise do processo de implementação. Anais do XVII Seminário sobre a Economia Mineira. Disponível em: https://diamantina.cedeplar. ufmg.br/2016/anais/politicas_publicas/125-197-1-RV_2016_10_09_00_54_58_626.pdf. Acesso em: 11 dez. 2016.

Brasil. 1988. Constituição da República Federativa do Brasil. Brasília: Senado Federal/Centro Gráfico.

Brasil. 2003. Decreto n. 4.887, de 20 de novembro de 2003. Regulamenta o procedimento para identificação, reconhecimento, delimitação, demarcação e titulação das terras ocupadas por remanescentes das comunidades dos quilombos de que trata o art. 68 do Ato das Disposições Constitucionais Transitórias. Disponível em: https://presrepublica.jusbrasil.com.br/legislacao/98186/decreto-4887-03. Acesso em: 14 mar. 2017.

Campos, L. A., e J. Feres Júnior. 2014. Ação afirmativa, comunitarismo e multiculturalismo: relações necessárias ou contingentes? Revista Brasileira de Ciências Sociais 29(84):103-118. DOI: https://doi. org/10.1590/S0102-69092014000100007

Feres Júnior, J., V. T. Daflon, e L. A. Campos. 2012. Ação afirmativa, raça e racismo: uma análise das ações de inclusão racial nos mandatos de Lula e Dilma. Revista de C. Humanas 12(2):399-414. 
Ferreira, V, e J. Medeiros. 2016. Fatores que moldam o comportamento dos burocratas de nível de rua no processo de implementação de políticas públicas. Cadernos EBAPE.BR 14(3):776-793. DOI: https:// doi.org/10.1590/1679-395129522

Instituto Brasileiro de Geografia e Estatística (IBGE). 2011. Censo Demográfico 2010. Cidades - Facaré dos Homens. Rio de Janeiro: IBGE.

Instituto de Terras de Alagoas (ITERAL). s/d. Comunidades quilombolas em Alagoas. Maceió: Instituto de Terras e Reforma Agrária de Alagoas. Disponível em: http://www.iteral.al.gov.br/dtpaf/comunidadesquilombolas-de-alagoas/comunidades-quilombolas-de-alagoas. Acesso em: 20 mar. 2018

Leite, I. B. 2005. Laudos periciais em debate. Florianópolis: NUER/ABA.

Lipsky, M. 1980. Street-level bureaucracy. New York: Russell Sage Foundation.

Lipsky, M. 2019. Burocracia de nível de rua. Dilemas do indivíduo nos serviços públicos. Brasília: ENAP.

Mello, J., G. Carvalho, C. Santos, S. Lacerda, e K. Favilla. 2014. Plano Brasil Sem Miséria e o atendimento de comunidades quilombolas. Cadernos de Estudos Desenvolvimento Social em Debate (20):197-211.

Moehlecke, S. 2002. Ação afirmativa: história e debates no Brasil. Cadernos de Pesquisa (117):197-217. DOI: https://doi.org/10.1590/S0100-15742002000300011

Monteiro, L. 2016. Modelo “top down”: uma reflexão sobre a implementação de políticas públicas e a participação dos gestores governamentais. Revista Gestão Organizacional 9(3):25-35.

Oliveira, V., e F. Abrúcio. 2018. Burocracia de médio escalão e diretores de escola: um novo olhar sobre o conceito, in Burocracia e políticas públicas no Brasil: interseções analíticas. Editado por R. Pires, G. Lotta \& E. O. Oliveira, pp. 207-225. Brasília: IPEA/ENAP. 
Rodrigues, V. 2010. Programa Brasil Quilombola: um ensaio sobre a política pública de promoção da igualdade racial para comunidades de quilombos. Cadernos de Gestão Pública e Cidadania 15(57):263278. DOI: https://doi.org/10.12660/cgpc.v15n57.3258

Secretaria de Políticas Públicas de Promoção da Igualdade Racial (SEPPIR). 2004. Programa Brasil Quilombola. Brasília: SEPPIR.

Secretaria de Estado do Planejamento, Gestão e Patrimônio (SEPLAG). 2015. Estudo sobre as comunidades Quilombolas de Alagoas. Maceió: SEPLAG.

Souza, S., e A. Brandão. 2017. Dilemas e desafios do acesso ao Programa Brasil Quilombola. A realidade vivenciada pelas comunidades Marques. Emancipação 17(2):217-232. DOI: https://doi.org/10.5212/ Emancipacao.v.17i2.0003

Teixeira, T. 2017. O ocaso do Programa Brasil Quilombola: uma análise orçamentária no Brasil e no Maranhão. Encontro da Associação Nacional de Pós-graduação e Pesquisa em Administração. 1-15 DOI: https://doi.org/10.13140/RG.2.2.14023.19367

Vieira, F. 2015. Andanças entre currais, dádivas e políticas públicas: o Programa Brasil Quilombola na comunidade Negros do Riacho em Currais Novos-RN. Dissertação de Mestrado, Universidade Federal do Rio Grande do Norte, Departamento de Ciências Sociais, Natal. 